\title{
On the Effect of Task-based Language Teaching on the Pragmatic Competence (Illocutionary Force) of the Iranian Male and Female Students
}

\author{
Iraj Noroozi \\ Department of Language Teaching and Translation, Varamin-Pishva Branch, Islamic Azad University, Varamin, Iran \\ Email: iraj_noroozi3459@yahoo.com
}

\begin{abstract}
The present research study, based on a systematic procedure, investigates the impact of the illocutionary and locutionary forces of the pragmatic competence on the Iranian male and female language teaching juniors. By virtue of gaining a persuasive and forceful ultimate goal of this study 400 language teaching Iranian juniors between 20 and 30 voluntarily took part in this study. They were initially exposed to the proficiency TEOFL test. Those who got over the 70 percent of the scores- 120 male and female subjectswere selected as the subjects of the study. This study subsumes three phases. Phase 1 witnessed a T-test where 60 males and females of the aforementioned subjects were randomly classified into two-30 subject groups. The experimental group was assigned tasks based on illocutionary act measures where the communicative force of the utterances was taken into account and the control group was given tasks based on locutionary act where the well-formedness of the utterances was considered for the period of twelve sessions. As the posttest five native like Iranian Ph.D holders in linguistics who had full command of pragmatic competence in general and speech act theory in particular were hired to interview all the 60 subjects to unravel their differences. The acquired result revealed that the experimental group was much more versed in pragmatic competence regarding the illocutionary force of speech act theory. Phase 2 was allotted to a correlational study. The researcher intended to look into the degree of correlation between the locutionary and the illocutionary forces. The scores of 30 subjects in illocutionary experimental group were correlated with those of the locutionary control group. The coefficient of correlation demonstrated that there was a negligible positive correlation between the two variables. In phase 3 a $2 \times 2$ factorial design was employed where the 120 male and female subjects selected by the TOEFL test were subjected to locutionary and illocutionary act. According to the observed $F$ it was proved that the females outperformed the male subjects in both locutionary and illocutionary acts.
\end{abstract}

Index Terms - correlation, factorial design, illocutionary, juniors, locutionary, pragmatic competence, t-test

\section{INTRODUCTION}

For the past 20 years, task-based language teaching (TBLT) has attracted the attention of the second language acquisition (SLA) researchers, curriculum developers, educationalists, teacher trainer, and language teachers worldwide. To a great extent, the introduction of TBLT into the world of the language education has been a 'topdown' process. The term was coined, and the concept developed, by SLA researchers and language educators, largely in reaction to empirical accounts of teacher-dominated, form-oriented second language class-room practice (Long \& Norris, 2000).

However, according to Nunan (1989) the current trends are basically evolutionary rather than revolutionary in nature, as methodologists and curriculum developers seek to add value to tried and tested practices rather than to subvert or reject them out of hand. Nowadays, the applied linguists dwell on how contemporary trends have added value to practice, or have prompted reassessment and reevaluation of practice in the areas of syllabus design, approaches to teaching, the role of the learner, approaches to language, the role of texts, resources and approaches to learning, classroom organization and assessment (p.35).

Stimulus for Change

\section{Ineffectiveness of Traditional Approaches}

Perennial stimulus for change in language education has been dissatisfaction with the results obtained by 'traditional' methods, often at great cost to schools and language systems, and the expenditure of tremendous effort by students and teachers. In grammar-translation classrooms, learners typically spent years learning English and yet many of them were still unable to use the language effectively. They often knew a good deal about the language but were unable to use this knowledge to communicate appropriately. In systems where grammar-translation gave way to audiolingualism, students were able to parrot responses in predictable situations of use, but had difficulty communicating effectively in the relatively unpredictable world beyond the classroom. Many concluded that it was a poor investment if all that work seemed to offer so little practical result. students had a basic foundation of language knowledge, but they do not know how to put that knowledge to active use. To help them to communicate and use that language knowledge, it was 
gradually recognized and accepted that a new approach to language learning and teaching was needed. Learners needed to understand that language is not just a list of grammatical patterns and a collection of words. Language as communication involves the active use of grammar and vocabulary to listen and read effectively and to speak with and write to other people. Language needs to be learned functionally so that learners are able to see that different forms communicate different meanings. One response to the perception that language educators are relatively ineffective, was to question to value of learning another language. It is believed that language learning should have a central place in any educational system. If we accept what Pinker (1994) and his colleagues have to say, then language is arguably the defining characteristic of the human species, and a knowledge of language in general, as well as an ability to use one's first, and at least one other language, should be one of the defining characteristics of the educated individual. As the bumper sticker says: "Monolingualism is curable!" In a world that is increasingly intermeshed economically, environmentally and electronically, the ability to communicate effectively is crucial (Nunan, 1989, pp. 34 - 36).

\section{Relevance of Language Teaching to General Education}

It is only through language that we can communicate with each other, share our ideas, tell people what we have experienced, express our wishes and desires, solve complex problems by drawing on information we read or hear, and, above all, communicate in the workplace and across cultures with people from other countries. To achieve these objectives, however, we need to learn language as communication not just as a list of facts to be memorized or a set of symbols to be manipulated. This, as we saw earlier has been an important force in the evolution of a new approach to language learning, one which begins from this active use of language and which involves learners in cooperative learning tasks using language, helped by their teachers and specially designed learning materials. This is a central aim of contemporary approaches to language teaching. The skills developed through the application of active, co-operative learning principles can flow through to other subjects as well. Effective foreign language learning produces learners with the social and cognitive problem solving skills that can be deployed in other subjects on the school curriculum. If only we could get language teachers and subject teachers communicating with each other, it might be possible to fashion a new type of school curriculum, one in which the familiar elements are not jettisoned, but recombined.

Then, the relevance of the intellectual knowledge, learning skills, interpersonal development and intercultural sensitivities fostered in the language classroom might be appreciated by others with a vested interest in education (Nunan, 1989, pp. $38-40$ ).

\section{WHAT IS A TASK?}

The concept of 'task' has become an important element in Syllabus design, classroom teaching and learner assessment. It underpins several significant research agendas, and it has influenced educational policymaking in both ESL and EFL settings. Pedagogically, task-based language teaching has strengthened the following principles and practices:

- A needs-based approach to content selection.

- An emphasis on learning to communicate through interaction in the target language.

- The introduction of authentic texts into the learning situation.

- The provision of opportunities for learners to focus not only on language but also on the learning process itself.

- An enhancement of the learner's own personal experiences as important contributing elements to classroom learning.

- The linking of classroom language learning with language use outside the classroom.

It is postulated that this is an important question to answer for two reasons. First, there is much inconsistency and confusion about what a task is at present. Second, a proper definition is necessary and important to the discussion of how the use of tasks should be able to promote SLA. The followings are some definitions of the term "task" one can find in the literature (Richards, Platt \& Weber, 1986 p. 289):

"...a piece of work undertaken for oneself or for others, freely or for some reward. Thus, examples of tasks include painting a fence, dressing a child, filling out a form, buying a pair of shoes, making an airline reservation, borrowing a library book, taking a driving test, typing a letter, weighing a patient, sorting letters, taking a hotel reservation.... and helping someone across a road. In other words, by 'task' is meant the hundred and one things people do in everyday life, at work, at play, and in between.

Long (1985) fastens on another definition (p. 89):

"An activity or action which is carried out as the result of processing or understanding language (i.e. as a response). For example, drawing a map while listening to a tape, listening to an instruction and performing a command, mat be refereed to as tasks. Task may or may not involve the production of a language. A task usually requires the teacher to specify what will be regarded as successful completion of the task. The use of a variety of different kinds of tasks in language teaching is said to make language teaching more communicative ...since it provides a purpose for a classroom activity which goes beyond the practice of a language for its own sake.

"...a piece of work or an activity, usually with a specified objective, undertaken as part of an educational course, or at work" (Crookes, 1986, p.112).

"...any structured language learning endeavour which has particular objective, appropriate content, a specified working procedure, and a range of outcomes for those who undertake the task. "Task' is therefore assumed to refer to a 
range of work plans which have the overall purpose of facilitating language learning--from the simple and brief exercise type, to more complex and lengthy activities such a group problem-solving or simulations and decision making" (Breen, 1987 p. 23).

"An activity which required learners to arrive at an outcome from given information through some process of thought, and which allowed teachers to control and regulate that process, was regarded as a 'task' (Prabhu, 1987, p. 24).

"...a piece of classroom work which involves learners in comprehending, manipulating, producing or interacting in the target language while their attention is principally focused on meaning rather than form (Nunan, 1989 p. 10).

"...an activity which involves the use of language but in which the focus is on the outcome of the activity rather than on the language used to achieve that outcome (Willis, 1990, p. 127).

"...some kind of activity designed to engage the learner in using the language communicatively or reflectively in order to arrive at an outcome other than that of learning a specified feature of the L2 (Ellis, 1994, p. 595).

These definitions differ in specificity. Long's definition which covers virtually everything people do, is a definition of the term in its general sense, with no particular reference to language teaching. The rest of the definitions all define the task in the pedagogical context. A difference here is that Breen's definition includes exercises while the rest of them do not. Based on the way most researchers define and use the term and the actual examples people give in their discussion of task-based language teaching, and following Hichey's (1993) approach to defining formulas by means of a preference rule system originally used by Jackendoff (1983, p. 55), some defining features of tasks are outlined below.

1. A task is an activity carried out for the ultimate purpose of language learning. Since the need for a clear definition of the term "task" rises because it takes on a particular meaning when being used in language teaching context, it is only reasonable to exclude activities carried out for purposes other than language teaching and learning.

2. A task is a meaning-oriented activity whereby the exchange of information is essential for its successful completion. This rules out those learning activities in which the learners' attention is focused on linguistic forms, such as imitation or pattern drills.

3. A task is an activity which leads to a specific outcome. The outcome can be a decision, a solution to a problem, an agreement reached among participants. This rules out activities which, though involving exchange of information, do not result in a specific outcome such as telling a story, questions and answers as independent tasks though they can be part of a task.

Based on these defining features, a task can be defined as a meaning-focused language learning activity which leads to a specific outcome at its completion. These defining features are the necessary conditions an activity has to meet to be considered as a task. Besides these conditions, a task typically employs language as the primary media for communication, though paralinguistic or any other means may be also involved. It should also have a definite beginning and ending point to make it a complete and independent activity. A task also typically has a set of procedures usually predetermined by the instructor for the learners to follow for its completion.

Long (1985) frames his approach to task-based language teaching in terms of target tasks, arguing that a target task is: a piece of work undertaken for oneself or for others, freely or for some reward. Thus, examples of tasks include painting a fence, dressing a child, filling out a form, buying a pair of shoes, making an airline reservation, borrowing a library book, taking a driving test, typing a letter, weighing a patient, sorting letters, making a hotel reservation, writing a cheque, finding a street destination and helping someone across a road. In other words, by 'task' is meant the hundred and one things people do in everyday life, at work, and at play. When they are transformed from the real world to the classroom, tasks become pedagogical in nature (p. 89). In this domain another perspective was presented in the mid-1970s by Lawrence Stenhouse who argued that at the very minimum a task-based curriculum should offer the following:

A. In planning

1. Principles for the selection of content - what is to be learned and taught.

2. Principles for the development of a teaching strategy - how it is to be learned and taught.

3. Principles for the making of decisions about sequence.

4. Principles on which to diagnose the strengths and weaknesses of individual students and differentiate the general principles 1, 2and 3 above to meet individual cases. (p. 175)

\section{What IS PRAGMATICS?}

Austin, (1962) maintains that the linguistic discipline known as Pragmatics is that branch of linguistics concerned with language in use or the study of meaning as it arises from language occurring in context. Pragmatics does not examine the relationship between the word and its definition or sense (the domain of semantics) but the relationships between words and the entities (real-world or otherwise) to which those words refer (referents or discourse entities). Furthermore, the linguist working in pragmatics is trying to account for utterances in terms of the meaning intended by the speaker and understood by the hearer.

Swain (1985) maintains that when we encode an utterance, our hearer or reader can use dictionary/grammar knowledge to decode it to the point of establishing its meaning in a kind of general-purpose sense. But the dictionary/grammar meaning of any utterance underdetermines its meaning in context: its "value", or the role it plays in the ongoing communication. To understand a sentence like Your driver will be here in half an hour, a hearer needs to 
feed a good deal of extra information into the utterance: the fact that in this instance the variable your refers to the hearer him/herself; the exact identity of the driver in question; the location of here; and the time frame within which in half an hour has to be calculated. None of this information is encoded in the grammar and semantics of the sentence itself. The sentence I still haven't forgiven her for the thing about the hedgehog and the music stand depends for its interpretation on shared knowledge that is in no way expressed by the language forms used. Correct interpretations of utterances can indeed take us a very long way away from their surface encodings. In specific situations the following sentences, for example, might be used to convey the messages shown in brackets (or other very different ones), and be successfully understood as doing so.

- Your coat's on the floor. ('Pick up your coat.')

- Jane's got her exams on Friday. ('I can't come to lunch.')

- Let's not have a repetition of last time. ('Don't get drunk and start flirting with Melissa.')

- It's Wednesday. ('Put the trash out.')

(p. 76)

\section{TASK-BASED LANGUAGE TEACHING}

TBLT started in the 1970s when scholars argued that language instruction should teach both grammar and meaning (Skehan, 2003, p. 145). The field widely takes Prabhu as one of the first proponents for tasks or TBLT when he started the approach in teaching secondary school classes in Bangalore, India in the 1970s (Ellis, 2003, p. 192). From then on, TBLT began to be recognized and widely discussed in language teaching and research in Second Language Acquisition (SLA).

Some of its proponents (e.g., Willis, 1996) believe that TBLT develops from communicative Language Teaching (CLT), the predominant language teaching approach since the 1970s, because TBLT shares the same several principles with CLT. From the 1980s, "task" and "task-based language teaching/instruction" have become increasingly preferred terms to those of "communicative activity" or "communicative language teaching" (Skehan, \& Swain, 2001 , pp.154 165).

Though TBLT is argued to have originated from CLT, it has its own rationales from different philosophies and approaches toward language instruction. Nowadays, TBLT is a broad term, which involves not only research and teaching, but testing and curriculum design in SLA. Crooks and Gass (1993) claim that TBLT is mainly used in two areas: "first, as an aspect of the research methodology used in studies of second language acquisition (SLA) from the beginning of the 1980s, and second, as a concept used in the second language curriculum design from the middle of the 1980s" (p.1). Recently Samuda and Bygate (2008) go beyond SLA and illustrate TBLT from an educational perspective. According to Samuda and Bygate (2008), "by 1913 Dewey was arguing that classroom learning needed to be focused and shaped so that it met the personally held interests that pupils brought with them, and the ends that they held in sight" (p. 19). That is, classroom learning should be connected with students' personal experiences, or classroom teaching should be authentic. The implication is that "we need to seek out new ways of teaching so that the content is accessible, useful and relevant given the levels of experience and understanding of learners" (Samuda \& Bygate, 2008, p. 20).

Willis (2007) maintains that the aim of language teaching worldwide is to enable learners to use the language they have learned in school or college to communicate confidently and effectively with other users of English in the world outside. This aim prioritizes fluency rather than accuracy. Learners should be able to use the language with speed and confidence even if this means sacrificing grammatical accuracy. A task-based approach, where learners actively engage in meaning focused activities, for much (but not all) of their time in class, is explicitly designed to achieve this. English teachers all over the world express the same worries. Teachers of Spanish and French in the UK have the same concerns. There is something seriously wrong with the way languages are taught in many classrooms. We believe that one of the problems is a failure to recognize that language is much more than a grammatical system. Learning a language involves Learning How to Mean as given in the title of Halliday (1975). A command of standard grammar is a part of this, but we need to recognize two things. As we have seen it is possible to have some knowledge of how the grammar works without being able to apply that knowledge. On the other hand it is possible to communicate effectively in a language for all kinds of purposes without conforming closely to a standard grammar. Most teachers are aware of this and many are aware that TBLT offers a realistic alternative to the traditional grammar-based approaches which have consistently failed our learners.

Among grammar-based approaches we would include PPP. In a PPP methodology learners are so dominated by the presentation and practice that at the production stage they are preoccupied with grammatical form rather than with meaning. We need to shift the emphasis in teaching foreign languages to a focus on understanding and expressing meanings. This almost certainly entails beginning with a more lexical approach and gradually integrating grammar once learners have a wide enough vocabulary to be able to see how grammar can help fine-tune their message. The purpose of this article is to address some of the questions which are constantly raised about TBLT and which perhaps get in the way of a much wider application of TBLT principles (pp. 120 -122).

\section{Communicative LAnguage TeAching (CLT)}


Communicative Language Teaching (CLT) is one of the most accepted paradigms in the language teaching circle that offers a new view of language. The concept derived from theories in a wide range of areas: philosophy, psychology, sociology, linguistics and educational research taking language learning as an educational and a political issue (Savignon, 1991, p. 265). It has been popular since 1970 when language teaching was taken up by scholars from different disciplines, especially those in psychology and linguistics. H. Douglas Brown defines CLT as a "unified but broadly based, theoretically well-informed set of tenets about the nature of language and of language learning and teaching" (Brown, 2007, p. 46). Since CLT is not a method, and is not even fixed to any particular pedagogical methods "as far as theories of learning and effective strategies in teaching are concerned" (Brandl, 2008, p.6), interpretation for classroom practice can be applied in various ways. The formation of this set of tenets is influenced by interdisciplinary works of scholars such as J. Firth, M. Halliday, D. Hymes, and J.L. Austin (Brandl, 2008, p. 4). One of the distinguished scholars is Savignon, who supports the application of this approach in the classroom using interpretations and manifestation. The conceptual insights about CLT became broader and available for interpretation and implementation. From Audiolingual's drill and repetitive activities, and Translation-Grammar's lack of oral competence, language teaching in CLT framework widens its scope of interests to both social and linguistic contexts that leads to the enrichment of communicative competence in learners. CLT is a effort to develop authenticity, real-world simulation and meaningful tasks in language classrooms. Therefore learners' linguistic fluency is focused (Brown, 2007, p. 45).

According to Brown (2007) the characteristics of CLT read as follows:

- With overall goals, all components of communicative competence as well as the organizational and pragmatic aspects of language are in play.

- By engaging learners in language use for meaningful purposes, pragmatic, authentic and functional use is encouraged and therefore correct forms can be excused though not totally ignored.

- To encourage comprehension and production with fluency in learners, correcting for accuracy can be offered by teachers subsequently.

- Focusing on real-world contexts, learners are equipped with skills they need for the unrehearsed contexts by communicative techniques.

- Individual learners' learning process is considered in order to promote their autonomy and strategic involvement. Teacher can help them develop appropriate strategies according to their strengths, weakness and preferences of learning styles.

- Teacher roles in CLT classroom are like those of 'coach,' 'guide' or 'facilitator' and 'friend' who will help learners develop genuine linguistic interactive competence. Therefore learners are active participants who involve trial and error in order to communicate by integrating different language skills.

Due to a variety of interpretations of CLT, there are diverse manifestations of it leading to CLT 'offshoots' such as Natural Approach, Cooperative Language Learning, Content-based Teaching, and Task-based Teaching. These offshoots can be viewed as the effort to minimize CLT limitations. Furthermore, its survival of more than three decades and numerous and continual research studies on relevant issues as well as publication of teaching materials about CLT are evident to claim that it is a successful paradigm in the language teaching discipline (p. 48).

\section{How does TBLT Relate to The Communicative Language TEACHING?}

Approaches to language teaching can be seen on a continuum from form-based to meaning-based. Form-based approaches rest on the assumption that language should be introduced or presented to learners item by item as a formal system. Once they have understood how a particular linguistic form is structured and used they can begin to use it for communication. Meaning-based approaches make the assumption that learners develop a language system through their attempts to use that language. The role of the teacher is to provide opportunities for meaningful activities, to organize exposure to language which will provide appropriate input for the learner's system, enabling natural acquisition, and to encourage learners to look critically at that input and learn from it, for example by finding a new way of expressing a particular meaning. TBLT developed from communicative approaches. In TBLT, a task is seen as central to the learning cycle. A task has a number of defining characteristics, among them: does it engage the learners' interest; is there a primary focus on meaning; is success measured in terms of non linguistic outcome rather than accurate use of language forms; and, does it relate to real world activities? The more confidently we can answer yes to each of these questions the more task-like the activity (Willis \& Willis, 2007, p. 13). So a task-based approach is very much towards the meaningbased end of the spectrum. Learners may engage with a task simply because the topic is appealing. For example, a group of teenagers asked to Work with a partner. What do you think makes a good party? May well find the topic intrinsically interesting and engage in discussion. But they are more likely to do this if they are given more specific instructions: Write a list and agree on the three most important ingredients of a good party (Kay \& Jones, 2000, p. 62). And the chances of meaningful interaction may be further increased if there is a teacher led introduction in which the teacher describes a really memorable party she attended and gives one reason why she found it so memorable. So a successful task starts with a basic idea but it is the way that idea is exploited that helps to ensure real learner participation. Our own experience in the classroom, our observation of classrooms, and our discussions with teachers over many years suggests that most, if not all, of these observations hold good in the majority of classrooms. And all of 
these observations reinforce the findings of SLA research. When we persist in a grammar-based approach with its overwhelming emphasis on accuracy we are flying in the face, not only of research, but also of our own classroom experience. There are a number of research studies which are concerned specifically with communicative language teaching and which are applicable to TBLT. Ellis (1994) summarizes the findings as follows:

1. Giving beginner learners opportunities for meaningful communication in the classroom helps to develop communicative ability and also results in linguistic abilities no worse than those developed through more traditional form-focused approaches.

2. Communicative classroom settings may not be sufficient to ensure the development of high levels of linguistic and sociolinguistic competence, although they may be very effective in developing fluency and effective discourse skills (p. 604).

By linguistic abilities Ellis means control of the grammar. Given that the proper goal of language tuition is the development of fluency and effective discourse skills rather than a narrow linguistic competence, Ellis can reasonably be taken as endorsing meaning-based approaches. Even if we have some doubts about the efficacy of such approaches we should still be prepared to give them a realistic trial, given the recognized failure of the more traditional methods outlined above. In the TBL approach proposed in Willis and Willis (2007) there is ample opportunity for learners to pay careful attention to language within the task cycle, and an explicit focus on form after the task cycle (pp. 130 - 173).

Long (1992) holds that among the recent innovations in the field of second language teaching, task-based language teaching is probably the most promising and productive one, the one which has drawn much attention from both second language teaching profession and second language researchers. Three distinctive variations of it have emerged over the last ten years. They all can be put under the general category of task-based language teaching because they all consider the use of content-based tasks as the most important feature of their innovations (p. 98).

However, they do differ from each other in some significant ways, particularly in terms of syllabus design. The first of them is characterized by having no predetermined syllabus and represented by Prabhu (1987) and Breen (1984), Advocates of this approach argue that the content of the language classroom should not be predetermined. Among the reasons they give, the following two are the most important. First, our current knowledge of second language learning process doesn't allow us to "clearly identify learning "items"" and "prespecify the optimum sequence for their presentation in order to optimize learning by the audience, whatever its size." (Candlin, 1984 p. 40), and second, even if we predetermine what is to be taught, we can't determine what is actually learned by our learners. The result is the "continuing disparity and conflict between intention and reality, between theory and realization." (Candlin, 1984 p. 32 ). To them a syllabus should be open and negotiable and they should be "retrospective records rather than prospective plans" (Candlin, 1984 p. 35).

In the second approach, as represented by researchers such as Long and Crookes (1992) and Nunan (1989, 1991), on the other hand, the syllabus does have predetermined content. However, different from traditional syllabuses which use grammar, lexis, notion or function as units of analysis, it is organized around the tasks which are derived from real-life tasks for pedagogical purposes and sequenced according to the complexity of the tasks (Long \& Crookes, 1992). The third variation, as represented by Willis (1990, 1993), Sheen (1994), Widdowson (1984), and Brumfit (1984), makes a clear distinction between syllabus and methodology. They adopts a traditional structural (grammatical or lexical) syllabus, but the method is task-based. They argue that it is the methodology that can be communicative or task-based, but "There is no such thing as a communicative syllabus" (Widdowson, 1984, pp. 77 - 85).

Advocates of task-based language teaching claim that such a teaching approach is "compatible with current SLA theory." (Long \& Crookes, 1992 p. 43). It has also been claimed that many studies have produced evidence which is in support of the effectiveness of this approach, specifically the use of tasks, in facilitating SLA. However, compared to the discussion of the practical aspects involved in this teaching approach, such as the designing of a task based syllabus and task derivation and sequencing, little has been done to explain the general question of how the use of tasks can better promote SLA than other teaching approaches, or, in the cases of the empirical studies, the results which are interpreted to support such claims, in terms of current SLA theory. In this paper I hope to answer three questions: what is a task? What does a task do as a learning activity? According to the current theory of SLA, broadly defined, how does the use of tasks facilitate SLA.

Skehan (1998) is persuaded that there are numerous theories and approaches to teaching a second language, some exotic some mundane but all have one thing in common - a desire to make the acquisition of a foreign or second language as efficient and effective as possible (p. 75).

Task Based Language Teaching (TBLT) is an approach which offers students material which they have to actively engage in the processing of in order to achieve a goal or complete a task. Much like regular tasks that we perform everyday such as making the tea, writing an essay, talking to someone on the phone, TBLT seeks to develop students' interlanguage through providing a task and then using language to solve it.

\section{SOME OF The Main Features of TBLT}

- there is some communication problem to solve

- there is some sort of relationship to comparable real world activities

- task completion has some priority 
- meaning is primary

- the assessment is done in terms of outcomes

On the other hand, tasks:

- do not give learners other people's meanings to regurgitate

- are not concerned with language display

- are not conformity oriented

- are not practice oriented

- do not embed language in materials so that specific structures can be focused on

which leads to some examples of tasks:

- completing one another's family tree

- agreeing on advice to give the writer of a letter to an agony aunt

- solving a riddle

- leaving a message on someone's answering machine

but which rule out:

- completing a transformation exercise

- most Q and A with a teacher

- inductive learning activities where preselected material is conducive to the

- generation of language rules

(Skehan, 1998, pp. 63 - 64).

From this we can see that tasks focus on form (rather than individual forms of many separate structures) and that learners have to actively negotiate meaning and produce communication to complete the task.

Skehan's list offers some exciting and fun possibilities. When tasks are introduce such as solving a crossword and then getting the students to make their own and then share it with each other, or read about a topic and watch a related video clip, students become engaged with language and meaning as well as intensive cognitive processing which induces interlanguage modification and development.

\section{STATEMENT OF THE PROBLEM}

Berwick (1988) maintains that one of the hotly debated issues in the realm of applied linguistics deals with the force of the practicality and feasibility of the task based language teaching (TBLT) in the educational arenas. On the other hand, the language practitioners are usually unaware of the impact of TBLT on the illocutionary force of the pragmatic competence. The problem of the sex of the language learners is also another focus in this respect. That is, language teachers are expected to know the different reaction that male and female learners show when they are exposed the components of TBLT to promote their illocutionary force of the pragmatic competence.

\section{STATEMENT Of THE HyPOTHESES}

In order to probe the foregoing issue and gain access to logical conclusions the following quantitative hypotheses were developed:

1. The task based language teaching has no impact on the illocutionary force of the pragmatic competence of language learners.

2. There is no correlation between illocutionary and locutionary forces of the pragmatic competence based on task based language teaching measures.

3. There is no interaction between sex and the illocutionary force of the pragmatic competence on the achievement of task based language teaching.

\section{SigNificANCE OF THE STUDY}

The ultimate goal of the researcher was directed to promote and ameliorate language teaching environments through the following contributions:

First and foremost, language teachers should be mindful of the essence of task based language teaching and get enough instructions on its pertaining components. Second, language teachers should be well familiar with the effective strategies of the task based language teaching components to advance the illocutionary force of the pragmatic competence of the language learners in order to manipulate them in their classrooms. Last but not least, language practitioners are also expected to be acquainted with the different sexes' capabilities of employing the illocutionary force of the pragmatic competence in task based language teaching.

\section{METHOD}

\section{Subjects}

In order to come up with conclusive and persuasive findings on the first null hypothesis forming the phase one of 
this study, 400 Iranian male and female students- 150 males and 250 females- between 20 and 30 years of age served as subjects. They were enrolled in a general English course at the Islamic Azad University, Varamin-Pishva branch. These subjects were given a TOEFL test (Barron's 1990) as a pretest. Following the correction of the papers, those who scored more than seventy percent of the total scores- 180 subjects of both sexes- where selected as the subjects of the study. The researcher employed a true experimental design in this respect.

TABLE 1.

TRUE EXPERIMENTAL DESIGN PERTAINING TO THE PHASE ONE
\begin{tabular}{|l|l|l|l|}
\hline $\mathrm{G}(\mathrm{E})$ & $\mathrm{T}(1)$ & $\mathrm{X}$ (Internal validity checked) & $\mathrm{T}(2)$ (external validity checked) \\
\hline $\mathrm{G}(\mathrm{C})$ & $\mathrm{T}(1)$ & $\mathrm{O}$ & $\mathrm{T}(2)$ \\
\hline
\end{tabular}

The researcher assigned 30 male and female subjects in the experimental group and 30 male and female subjects in the control group. These subjects had been randomly selected out of the aforementioned 180 subjects. Therefore, it could be considered that both groups were almost of the same language knowledge. The experimental group was assigned tasks based on illocutionary act measures where the communicative force of the utterances was taken into account while the control group was assigned tasks on locutionary act measures where the correctness of the utterances was the core of the attention. As the posttest five native like Iranian Ph.D holders in linguistics who had full command of pragmatic competence in general and speech act theory in particular were hired to interview all the 60 subjects to unveil their differences. The acquired findings based on the pertinent test statistical measures unraveled that the experimental group was much more versed in pragmatic competence regarding the illocutionary force of speech act theory.

The second null hypothesis making phase two of the research was to be probed Through a correlational study. The researcher intended to look into the degree of correlation between the locutionary and the illocutionary forces of the pragmatic competence based on task based language teaching measures. The scores of 30 subjects in illocutionary experimental group were correlated with those of the locutionary control group. The coefficient of correlation demonstrated that there was a negligible positive correlation between the two variables. In other words, the correlation coefficient was around $+10 \%$.

In phase three a $2 \times 2$ factorial design was employed where the other 120 male and female subjects selected by the TOEFL test who had not been subjected to any treatment or placebo were subjected to locutionary and illocutionary act measures. Hereunder the relevant table can be observed.

TABLE 2.

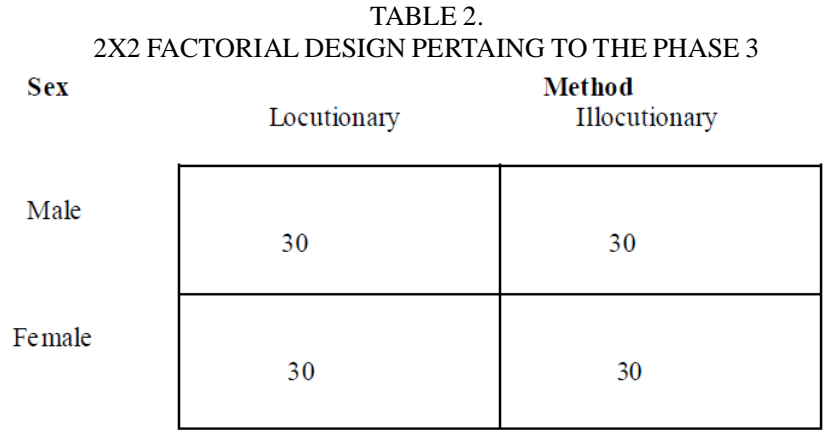

According to the observed $\mathrm{F}$ it was proved that the females outperformed the male subjects in both locutionary and illocutionary acts.

\section{CONCLUSION AND PEDAGOGICAL IMPLICATIONS}

"Pragmatics," for language teachers, is to do with what is encoded. Languages do not leave their speakers to grapple unaided with the problem of bridging the gap between the dictionary/grammar meanings of utterances and their precise value in communicative contexts. All languages provide ways of reducing the problem by labeling, in general terms, the typical communicative roles that utterances can take on. So, language teachers are expected to know and transfer the pragmatic competence in general and illocutionary acts in particular to the language learners. Put simply, the learners should be able to encode linguistically the fact hat that they are asking a question, or expressing doubt, or adding information, or showing respect, or making an objection, or exaggerating. It is these language-specific features that count as the overall language communicative competence. It is also important for the language teachers to know the differences between male and female learners as to how they react to the components of the pragmatic competence in general and illocutionary acts in particular. In the long run, the applied linguistics authorities should equip the language practitioners with the on the job training to familiarize them with the pragmatic competence and the illocutionary acts knowledge and give them the guidelines as to how to manipulate them in the language arenas.

\section{REFERENCES}


[1] Austin, J. L. (1962). How to Do Things With Words. New York: Oxford University Press.

[2] Berwick, R. F. (1988). The effect of task variation in teacher-led groups on repair of English as a foreign language. Unpublished doctoral dissertation. Vancouver, Canada: University of British Columbia.

[3] Brandl, D. (2008). Teaching language: From grammar to grammaring. Boston, MA: Thomson Heinle.

[4] Breen, M. P. (1987). Learner contribution to task design. N.J.: Prentice Hall.

[5] Brown, D. (1967). First things first. Harlow: Longman

[6] Brown, D. (2007). Teachers exploring tasks in English language teaching. Houndmills: Palgrave MacMillian.

[7] Brumfit, T. (1984). Planning class work: A task-based approach. Oxford: Heinemann.

[8] Candlin, E. F. (1984). Present day English for foreign students (4th edn.). London: London University Press.

[9] Crookes, J. (1992). TBLT, from theory to practice. London: Longman.

[10] Crooks, B. \& Gass, J, (1993). The handbook of pragmatics. Oxford: Blackwell.

[11] Dell, H. (2008). Implementing task-based learning with young learners. ELT Journal, 56(4), 389-396.

[12] Ellis, R. (2003). Task-based instruction in foreign language education. Washington: Georgetown University Press LI.

[13] Elllis, R. (1994). Task-based language learning and teaching. Oxford: Oxford University Press.

[14] Firth, J. (2008). Important tasks of English education: Asia-wide and beyond. Asian EFL Journal, 7(3), 20-27

[15] Gass, F. (1994). Preparing and implementing a task-based ESL curriculum in an EFL setting: implications for theory and practice. TESL Canada Journal, 11(2), 9-12.

[16] Haliday, D. (1975). Presumptive meanings: The theory of generalized conversational implicature. Cambridge, MA: MIT Press.

[17] Hichey. G. (1993). Teaching language as communication. Oxford: Oxford University Press.

[18] Jackendoff, D. (1983). Understanding utterances: The pragmatics of natural language. Oxford: Blackwell.

[19] Kay, M. \& Jones, F. (2000). The task-based approach: Some questions and suggestions. ELT Journal, 58(4), 319-326

[20] Long, M. H. (1992). Task, groups, and task-group interactions. In S. Anivan (Ed.), Language teaching methodology for the nineties. Singapore: RELC.

[21] Long, M. H. (1985). Three approaches to task-based syllabus design. TESOL Quarterly, 26(1), 27-56.

[22] Long, M. H. \& Norris, C. (2006). Task-based language education: From theory to practice. Cambridge: Cambridge University Press.

[23] Long, M. H. \& Crookes, N. (1992). It's always more difficult than you planned: Teachers' perceived difficulties in introducing the communicative approach in South Korea. TESOL Quarterly, 32, 677-703.

[24] Nunan, D. (1989). Important tasks of English education: Asia-wide and beyond [Electronic version]. Asian EFL Journal Vol. 7 , Issue 3.

[25] Prabhu, N. S. (1987). Second language pedagogy: A perspective. Oxford: Oxford University Press.

[26] Richard, J. Platt, B. \& Weber, C. (1989). Task-based instruction in foreign language education. Washington: Georgetown University Press.

[27] Samuda, F., \& Bygate, L. (1998a). Task-based instruction. Annual Review of Applied Linguistics, 18(2), 268-286.

[28] Savignon, M. (1991). Sociolinguistics. London: Penguin.

[29] Sheen, P. (1994). A framework for the implementation of task-based instruction. Applied Linguistics, 17(1), 38-62.

[30] Skehan, P. (2003a). Task-based instruction. Annual Review of Applied Linguistics, 18, 268-286.

[31] Skehan, P., Swain, M. (2001). A cognitive approach to language learning. Oxford: Oxford University Press.

[32] Skehan, P. (1998). Task-based learning: The interaction between tasks and learners. ELT Journal, 57(4), 352-360.

[33] Swain, M. (1985). A critical look at the communicative approach. ELT Journal 39(1), 32-35

[34] Stenhouse, L. (1979). Task-based language teaching. Oxford: Basil Blackwell.

[35] Widdowson, H. G. (1984). Teaching language as communication. Oxford: Oxford University Press.

[36] Willis, J. (1990). Teaching through pragmatics. Oxford: Longman.

[37] Willis, J. (2007). A framework for task-based learning. London: Longman.

[38] Willis, J.\& Willis, P. (2007). Task-based learning: The interaction between tasks and learners. ELT Journal, 57(4), 352-360

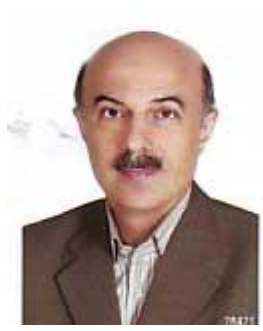

Iraj Noroozi was born in Tehran, Iran in 1955. He obtained his BA in English language translation from Allameh Tabatabaee state university in 1978. Afterwards, he got his MA in language teaching from the Azad University located in Tehran, Iran in 1995. In the long run, he studied for five consecutive years to receive his $\mathrm{PhD}$ in language teaching along with high average from Azad university situated in Tehran, Iran in 2005.

He has been teaching English and French in various institutions, But his main job is in the Azad University as an ASSISTANT PROFESSOR. He has also the command of French and German and speaks these two languages fluently. He has got seven of his books concerning general and specialized language teaching published thus far. He has also presented fifteen of his articles in different universities in Iran along with getting some prizes for some of them. He has conducted three research projects in the area of his specialtythat is, language teaching so far. His research interest is in the domain of reading comprehension.

Dr. Noroozi is an official member of the faculty in the Azad University located in Iran. He has been the head of the language department for three years. He has been the head of the college of literature and humanities for three years as well. He has also been selected as the member of the committee select and has been performing his job in this area too. He has been chosen as the best professor in the university for two years, i.e., 2006 and 2012. He has also been selected as the best researcher in his university in 2009. His prevailing hobbies are jogging and mountain climbing. 